\title{
İnebolu Orman İşletme Müdürlüğündeki Anadolu Kestanesi (Castanea sativa Mill.) Ormanlarının Meşçere Kuruluşu ve Doğal Gençleşme Örnekleri
}

\author{
*Osman TOPAÇOĞLU ${ }^{1}$, Esra Nurten YER ${ }^{1}$, Recep BAYCAN ${ }^{2}$ \\ ${ }^{1}$ Kastamonu Üniversitesi, Orman Fakültesi, Orman Mühendisliği Bölümü, Kastamonu \\ ${ }^{2}$ Nallıhan Orman İşletme Müdürlüğü, Andız Orman İşletme Şefliği, Ankara \\ *Sorumlu Yazar: otopacoglu@kastamonu.edu.tr
}

Geliş Tarihi: 31.10 .2016

\begin{abstract}
Özet
Anadolu'nun yerli bir türü olan Castanea sativa Mill. Kastamonu ilinin Karadeniz kiyısındaki ormanlarda geniş bir yayılış alanına sahiptir. Ormanlardan elde edilen ürün ve hizmetlerin sürekli bir şekilde sağlanması meşcere kuruluşlarına uygun silvikültürel işlemlerin gerçekleştirilmesi ile mümkün olmaktadır. Bu nedenle Kestane ormanlarının kuruluş ve doğal gençleşme özelliklerinin belirlenmesi biyolojik çeşitlilik ve doğa koruma açısından büyük önem taşımaktadır. Bu çalışmada; Kastamonu ili İnebolu İşletme Müdürlüğündeki Anadolu kestanesi (Castanea sativa Mill.) ormanlarının meşcere kuruluşları ve doğal gençleşme örnekleri araştırılmıştır. Ayrıca doğal gençleşme örneklerindeki vitalite (yaşam gücü) durumu ayrıntılı olarak ele alınmıştır. Bu sayede elde edilen veriler yardımı ile meşcere kuruluşları değerlendirilerek bu kuruluşları olușturan faktörlerin etki şekilleri belirlenmiş uygun işlemler ile gerek doğal gençleşme gerekse meşcere vitalite ve stabilitesini sürekli sağlayacak işletmecilik tekniğine vurgu yapılarak doğaya yakın silvikültürün altlıklarının oluşturulması amaçlanmıştır. Araştırma sonuçları değerlendirildiğinde; meşcere kapalılık derecesinin "gevşek 1şıklı kapalılık" olduğu yerlerde yoğun gençlik gruplarının yer aldığı meşcerenin "tam ve sıkıșık kapalılık" olduğu yerlerde ise gençliğin daha az yoğunlukta var olduğu tespit edilmiştir. Gençliğin dağılımında yamaç durumu dikkate alındığında alt yamaç ile üst yamaç arasında önemli bir farkın olmadığı belirlenmiştir. Vitalite sınıfının belirlenmesi amacıyla seçilen örnek bireylerin çoğunun 4. ve 5. vitalite sınıflarında yer aldığı görülmüştür. 1,2 ve 3. vitalite sınıflarına ise hiçbir örnek alanda rastlanmamıştır. Bu durum gençliklerin büyük çoğunluğunun yeterli boy ve çap artımı yapabildiğinin göstergesi olmuştur. Varlığı son yıllarda biyotik etkenler yüzünden tahrip olan kestane ormanlarının doğal gençleşme özellikleri üzerinde önemle durulması gerekmektedir. Kestane meşçerelerinin doğal olarak gençleştirilmesi veya doğal olarak gelmiş gençliklerde devamlılığının sağlanması yönünde uygun planlamalar bu alanlarda başlatılmalıdır.
\end{abstract}

Anahtar Kelimeler: Silvikültürel işlemler, Süreklilik ilkesi, Meşcere kuruluşu, Vitalite, Anadolu kestanesi (Castanea sativa Mill.)

\section{The Stand Structure of the Anatolian Chestnut (Castanea sativa Mill.) Forests and Samples of Natural Regeneration in Inebolu Forestry Enterprise}

\begin{abstract}
Castanea sativa Mill., which is a native strain of Anatolia, has an extensive range in the forests on the shore of Black Sea at Kastamonu province. Providing products and services, which are obtained from the sustainable forests, becomes possible by carrying out the silvicultural processes that are consistent with the stand structure. Therefore, determining the stand structure and natural regeneration characteristics of the forests, have great importance with regard to biological diversity and natural conservation. In this study, the stand structure of the Anatolian Chestnut forests and natural regeneration examples have been researched. Additionally, the vitality status in natural regeneration examples has been considered in detail. Thus, after evaluating the structure of the stands with the help of the data collected, the types of effects of the factors instituting these structures have been identified; and by expressing the administration technique that will continuously provide stand vitality, stability, and natural regeneration with appropriate processes; it is aimed to establish the basis of the silviculture, which is close to the nature. When the results of the study are evaluated; it is identified that, the intense youth groups take place in the areas where the closure level of the stand is "loose-light closure", and the youth is less intense where the stand has "whole and crown closure". When the statuses of the slopes are considered for the distribution of the youth, it is identified that there isn't a significant difference between the lower and higher slopes. It is seen that, the majority of the sample individuals, which were selected in order to determine the classes of vitality, took places in the $4^{\text {th }}$ and $5^{\text {th }}$ classes of vitality. And, the $1^{\text {st }} 2^{\text {nd }}$ and $3^{\text {th }}$ classes of vitality were not come across
\end{abstract}


in any of the sample areas. This situation has been an indicator of the fact that, a gross majority of the youth is able to have adequate amount of height and diameter increment. The natural regeneration characteristics of the chestnut forests that have been ruined in recent years because of biological effects should be emphasized with more stress. Plans in the direction of, naturally regenerating the chestnut stands or providing the continuity of the naturally obtained youth, should be initiated.

Key Words: Silvicultural processes, Sustainable system, Stand structure, Vitality, Anatolian chestnut

\section{Giriș}

Anadolu kestanesi (Castanea sativa Mill.) Türkiye'de yayılış yapan önemli bir ağaç türüdür. Kestane'nin Türkiye'deki yayılış alanı Rusya sınırından başlayarak Karadeniz k1yısı boyunca uzanmakta ancak daha batıda Istrancalar'1 geçmemektedir. Marmara çevresinde (özellikle Kapıdağ yarımadası) ve batı Anadolu'da saf ve karışık meşcereler halinde de bulunmaktadır. Tabii yayılış alanı tamamen Akdeniz rejyonu sınırları içerisinde kalmaktadir. H. Mayr'e atfen Erdem (1951) kestanenin bu rejyonun vejetasyon süresi altı aydan fazla olan Castanetum alt zonunun bir karakter ağacı olduğunu belirtmiştir. Anadolu kestanesi (Castanea sativa Mill.) Kastamonu ormanlarının \% 1'ini, İnebolu ormanlarının ise \% 15'ini oluşturmaktadır. Eski Yunan ve Romalı tarihçiler Yunanistan, İtalya ve İspanya'ya kestanenin Kastamonu (Kastanis)'dan getirildiğini bildirmişlerdir (Soylu ve ark., 2009). Dolayısıyla bu ağaç türü mitolojik açıdan da ayrı bir önem taşımaktadır. Türkiye dişında birçok ülkede yayılış gösteren Anadolu Kestanesi (Castanea sativa Mill.) odunu yanında meyve üretimi bakımından önemli bir gelir kaynağ1 oluşturmaktadır.

Orman Genel Müdürlüğü’nün 2013-2017 yıllarını kapsayan Kestane Eylem planında 60 bin ton kestane üretimi ile Türkiye; Çin ve G.Kore'den sonra dünyada üçüncü sırada yer almaktadır. $\mathrm{Bu}$ miktarın dünya kestane üretiminin yaklaşık \%3'nü karşıladığına dikkat çekilmiştir (Anonim, 2012). Türkiye'de kestane meyve üretimi, özel mülkiyetteki kestaneliklerden ve devlet ormanlarından gerçekleştirilmektedir.

Türkiye'de kestane meyvesi üretimi TÜIKK verilerine göre 1988 de 90 bin ton iken 2011 y1lında 60 bin ton olarak belirlenmiştir. Bu yıllar arasında inişli çıkışlı bir grafik izlese de genel olarak üretimde azalma söz konusudur. TÜiK verilerine göre, Kastamonu'da üretilen yıllık kestane miktarının \%50'sinden daha fazlası İnebolu ilçesinde üretilmektedir. Nitekim 2010 y1lında Kastamonu'da 9225 ton kestane üretilirken Ínebolu'da 6350 ton, 2011 y1lında Kastamonu'da 6904 tona karşı İnebolu'da 3285 ton kestane üretimi yapılmıştır. $\mathrm{Bu}$ da Kestane meyvesi üretimi açısından İnebolu ilçesinin önemini göstermektedir (URL 1).

Egzotik hastaliklar olarak bilinen zararlıların yayılması sonucunda dünyada kestane ormanlarında büyük zararlar meydana gelmiştir (Lovett ve ark., 2006; Liebhold ve ark., 2013). Anadolu kestanesi (Castanea sativa Mill.) de özellikle Kestane dal kanseri (Cryphonectria parasitica) ve mürekkep hastalığını (Phytophtara cambivara) olumsuz etkileri neticesinde geniş alanlarda tahribat görmüş, hatta bu alanlarda ağaç ölümleri ve ürün kayıpları meydana gelmiştir. Zarar gören kestane ormanlarının restore edilmesi ve tahribatın önüne geçilmesi amacıyla birçok araştırma gerçekleştirilmiştir. Araştırmalarda bu zararlılara karşı dayanıklı türlerin belirlenmesi ve geliştirilmesinin yanı sıra silvikültürel uygulama yöntemleriyle de çözüm yollarına başvurulmuştur (Clark ve ark., 2012).

Anadolu kestanesi (Castenea sativa Mill.) üzerine yapılan araştırmalarda türün doğal yayılışı, botanik, yetişme ortamı ve genotipik özellikleri ve zararlılarıyla ilgili çalışmalar gerçekleştirilmiştir (Soylu ve Ufuk, 1994; Gürer, 1999; Akça ve Y1lmaz, 1999; Serdar ve Soylu, 1999; Serdar, 1999; Çeliker ve Onoğur, 2001; Serdar 2002; Ozkan, 2003; Karagöz ve Gençsoylu, 2004; Ertan ve ark., 2007; Koyuncu ve ark., 2008; Soylu ve ark., 2009; Serdar ve ark., 2009; Serdar ve ark., 2010).

Vitalite (Yaşama Gücü) terimi gençliklerin veya küçük ağaçların nispi kuvvetliliğinin kantitatif tahmini ile ilgilidir. Özellikle gençliğin genel olarak yaşamda kalma 
potansiyeli ve devamlı gelişimi iyi ise yüksek vitaliteye sahiptir (Balc1, 2007; Çoban 2007). Yaşam gücü yüksek bireylerden oluşan gençlik ileride stabil orman kuruluşunun oluşumuna hizmet etmektedir. Meşcere kuruluşu meşcerede bulunan ağaç ve diğer bitkilerin fiziksel ve zamansal dağ 1 lımı olarak ifade edilir ve belirlenmesi uygulanacak silvikültürel müdahalelerin şekillenmesinde büyük öneme sahiptir (Smith ve ark., 1997).

$\mathrm{Bu}$ araştırmada gerek odun kalitesi gerekse meyve üretimi açısından değerli bir tür olan kestanenin araştırma alanındaki bazı meşcere kuruluşlarının özellikleri ortaya konulmaya çalışılmıştır. Ayrıca kestane gençliklerinin vitalitesi tespit edilerek başarılı gençleştirme çalışmaları için gerekli bilgilerin elde edilip değerlendirmesi amaçlanmıştır.

\section{Materyal ve Yöntem}

Materyal

Araştırma alanı olarak İnebolu Orman İșletme Müdürlüğü sahasında bulunan kestane ormanları belirlenmiştir.

Araştırma alanı Greenwich başlangıç meridyenine göre; $33^{\circ} 47^{\prime} 52^{\prime \prime}-33^{\circ} 55^{\prime} 48^{\prime \prime}$ doğu boylamları ile $41^{\circ} 48^{\prime} 07^{\prime \prime}-41^{\circ} 58^{\prime} 33^{\prime \prime}$ kuzey enlemleri arasinda bulunmaktadir. $\mathrm{Bu}$ alanda ormanlar Karadeniz sahilinden hemen sonra başlayarak $1657 \mathrm{~m}$ yükseltide yayılış göstermektedir.

Bölge Euro-Siberian fito-coğrafik rejyon olarak adlandırılan kısmında yer almakta olup yaprakl1-iğne yaprak ağaç türlerinden oluşan orman kuruluşları ile temsil edilmektedir (Şekil 1). İnebolu Meteoroloji İstasyonu verilerine göre y1llık ortalama sicaklık $13.1{ }^{\circ} \mathrm{C}$ ve ortalama nisbi nem $\% 75^{\prime}$ dir.

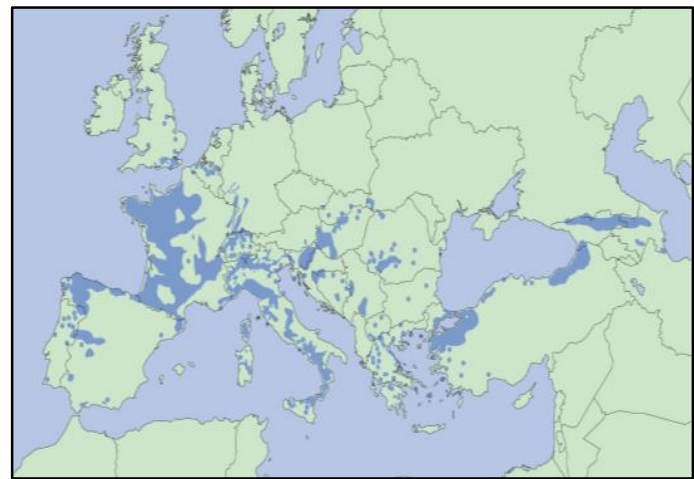

Şekil 1. Anadolu kestanesi'nin (Castanea sativa Mill.) yayılış alanı
Karadeniz sahil șeridinde yer alan İnebolu İşletme Müdürlüğü sınırlarında yayılışını gerçekleştiren Anadolu kestanesi (Castanea sativa Mill.) meşcere kuruluşları ve doğal gençleşme örneklerinin irdelenmesi araştırma konusunu oluşturmaktadır (Şekil 2).

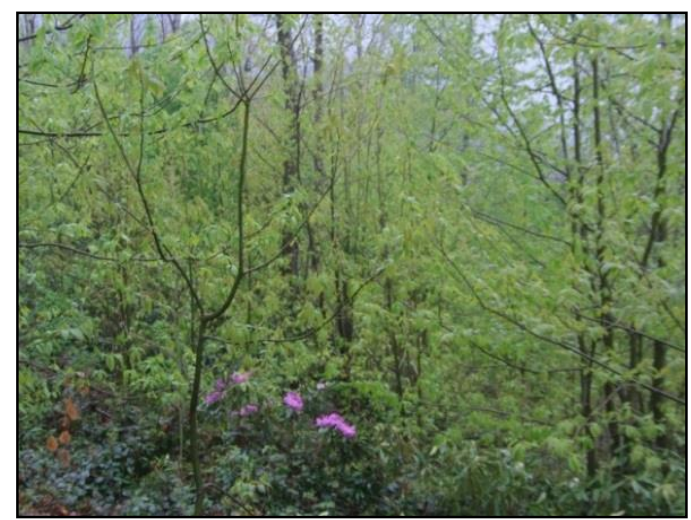

Şekil 2. İnebolu Orman İşletme Müdürlügü Kestane Alanlarından Görünüm

\section{Yöntem}

Araştırma alanının meșcere kuruluşu ile doğal gençleşme örnekleri arasındaki ilişkileri ayrıntılı bir şekilde ortaya koyabilmek amaciyla 10x50m ebatlarında $500 \mathrm{~m}^{2}$ büyüklüğünde 15 adet örnek alan alınmıştır (Şekil 3).

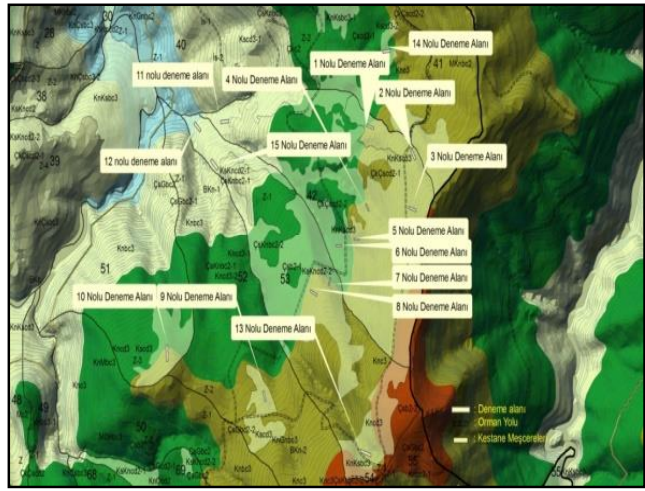

Şekil 3. Örnek alanların gösterimi

Örnek alanlar, yamacın farklı kısımlarındaki doğal gençleşme örneklerindeki değişimleri ortaya koymak amaciyla alt, orta ve üst yamaçlara dağıttılmıştır. Alt yamaçlardan 3, orta yamaçtan 7 ve üst yamaçtan 5 'er tane olmak üzere toplamda 15 örnek alan alınmıştır.

Meşcere profili alım yönteminde beş metrenin altındaki tüm bireylerin ölçümü yapılmıştır. Meşcere profili yanında ayrıca 
aynı ölçekte ikinci bir profille yalnızca gençlikler alınmış, bunlar daha sonra tek profil üzerinde birleştirilmiştir. Böylece meşcere kuruluşu özellikleri ile gençlik arasında ilişki tespit edilmeye çalışılmıştır. Meşcere profili ile; kapalılık derecesi, katlılık, ağaç türü bileşimi, göğüs yüksekliğindeki ağaç çapı, ağaç boyu, yaş ve kuru ve yaş dal yüksekliği (doğal dal budanması) belirlenmiştir.

Vitalitenin diğer bir belirtisi gençliğin büyüklüğüne (boy, çap) uygun olarak boy artışının oldukça yüksek olmasıdır. Araştırmada vitalite sınıflandırması Darabant ve ark. (2001)'e göre belirlenmiştir. Bu sayede elde edilen veriler yardımı ile doğal gençleşme sonucunda oluşmuş doğal gençliklerin vitalite (yaşama gücü) durumunun "vitalite sinıfları" yöntemi ile belirlenmiştir.

Araştırma alanındaki gençliklerin vitalite durumunu belirlemek amaciyla gençlik konilerinin görüldüğü alanlarda (A.K: Alt kenar, O.K: Orta Kısım, Ü.K: Üst kenar) gençliklerde yaş ve boy ölçümü yapılmıştır.

\section{Bulgular}

Araştırma alanında saf ve karışı kestane meşcerelerinin toplam sahas 7575.8 ha.' dır. İşletme müdürlüğünün toplam ormanlık alanı 47200.1 ha'dır. Kestane ormanları 499.8 ha saf meşcere, 6410.4 ha karışık, 665.6 ha bozuk meşcere kuruluş özelliği göstermektedir (Tablo 1).

Bu sahalarda Kestane meşcereleri 30 metre rakımdan 1120 metre rakıma kadar yayılış yapmakla beraber genellikle $300-1000 \mathrm{~m}$ rakımlarda karışık meşcereler oluşturmaktadır.

Araştırma alanındaki kestane ormanlarının yayıllış1 incelendiğinde genelde nemli kuzeye bakan bakılarda Fagus orientalis L. (Doğu kayın1), Pinus nigra Arnold. (Karaçam), Pinus sylvestris L. (Sarıçam) ve Carpinus orientalis Mill. (Gürgen) ile karışım yapmaktadır. Gençlik konilerinde yamaç durumu değerlendirildiğinde alt yamaç ile üst yamaç profilleri asarında önemli bir fark tespit edilmemiştir.

Tablo 1. İnebolu Orman İşletme Müdürlüğü'ndeki Anadolu Kestanesi (Castanea sativa Mill.) alanlarının şeflik bazında dağılımı

\begin{tabular}{|c|c|c|c|c|c|c|c|c|}
\hline \multicolumn{9}{|c|}{ İnebolu Orman İşletme Müdürlüğü Plan Verileri } \\
\hline \multirow[b]{2}{*}{ ŞEFLİĞ } & \multirow{2}{*}{$\begin{array}{l}\text { Ormanlı } \\
\text { k saha } \\
\text { (ha) }\end{array}$} & Ormansı & \multirow{2}{*}{$\begin{array}{l}\text { Saf } \\
\text { Kestan } \\
\text { e } \\
\text { meşcer } \\
\text { e sahası } \\
\text { (ha) }\end{array}$} & \multirow{2}{*}{$\begin{array}{l}\text { Kestane } \\
\text { karışım } \\
\text { I yapan } \\
\text { meşcere } \\
\text { sahası } \\
\text { (ha) }\end{array}$} & \multirow{2}{*}{$\begin{array}{l}\text { Bozuk } \\
\text { Kestan } \\
\text { e sahası } \\
\text { (ha) }\end{array}$} & \multirow{2}{*}{$\begin{array}{l}\text { Kestane } \\
\text { ağacını } \\
\text { n servet } \\
\text { miktarı } \\
\left(\mathbf{m}^{3}\right)\end{array}$} & \multirow{2}{*}{$\begin{array}{l}\text { Kestane } \\
\text { ağaçlarını } \\
\text { n ara } \\
\text { hasılat } \\
\text { etası }\left(\mathbf{m}^{3}\right)\end{array}$} & \multirow{2}{*}{$\begin{array}{l}\text { Topla } \\
\text { m yıllık } \\
\text { eta } \\
\text { miktarı } \\
\left(\mathbf{m}^{\mathbf{3}}\right)\end{array}$} \\
\hline & & $\begin{array}{l}\text { z saha } \\
\text { (ha) }\end{array}$ & & & & & & \\
\hline ALTINKUM & 6865.5 & 3688.1 & 30.5 & 1010.8 & 121.6 & 12705 & 2887 & 10363 \\
\hline $\begin{array}{l}\text { DOĞANYUR } \\
\text { T }\end{array}$ & 6697.2 & 3530.8 & 311.2 & 1480.3 & 311.6 & 42827 & 11755 & 10153 \\
\hline İNEBOLU & 11233.8 & 1698.8 & 35.1 & 1172.2 & 0.0 & 157956 & 5676 & 33131 \\
\hline GEMICILER & 11966.1 & 6318.6 & 30.4 & 1801.4 & 4.9 & 246413 & 7012 & 23208 \\
\hline ÖZLÜCE & 10437.5 & 4052.3 & 92.6 & 945.7 & 227.5 & 105367 & 2933 & 13023 \\
\hline \multirow{2}{*}{ TOPLAM } & 47200.1 & 19288.6 & 499.8 & 6410.4 & 665.6 & 565268 & 30263 & 89878 \\
\hline & 66488.7 & & 7575.8 & & & & & \\
\hline
\end{tabular}




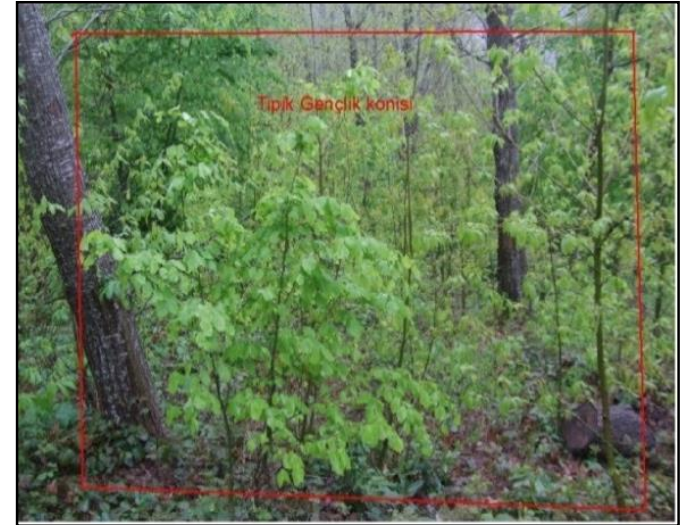

Şekil 4. Kestane meşcerelerinde tipik kestane konileri

Tablo 2 değerlendirildiğinde örnek alanların 307-941 m yükseltiler arasında değiştiği görülmektedir. Meşcere ortalama çap1 25.6-76.0 cm., meşcere ortalama boyu 14-17.80 m., meşcere hacmi ise 246.00$1078.00 \mathrm{~m}^{3} / \mathrm{ha}$ olarak tespit edilmiştir. Kestane ormanlarının araştırma alanında \%25-65 eğim aralı̆̆ında yayılış gösterdiği görülmüştür.

Araştırmada gençliklerin oluşumunda olumlu veya olumsuz etkenler gözlemlenerek Anadolu Kestanesi (Castanea sativa Mill.)'nde doğal gençleşme örnekleri analiz edilmiştir (Şekil 4).

Araştırma alanında meşçere kapalılığının düşük olduğu dolayısıyla meşcere içerisine kolaylıkla yeterli ışığın girebildiği alanlarda kestane doğal gençliğinin de kolaylıkla geldiği görülmüştür. Ayrıca meşçere altında bulunan diri örtü'nün (Rhododendron ponticum-orman gülü; Rubus platyphyllosböğürtlen; Vaccinium arctostaphylos-ay1 üzümü vs.) yoğun olduğu yerlerde doğal gençliklerin oluşamadığ ayrıca ağaç türleri ile karışım yapmış olan kestane meşçerelerinde kestane doğal gençliklerinin diğer ağaç türleri gençlikleriyle rekabet halinde olduğu ve nispeten diğer türlere göre daha az sayıda olduğu gözlemlenmiştir.

Yaşl1 kestane bireylerinde ise yoğun bir şekilde kestane dal kanseri zararı tespit edilmiş ve kurumaların olduğu görülmüştür. Alan üzerindeki incelemelere göre hastalığın takriben 10 yıldır devam ettiğ i ve tüm yaşlı ağaçlarda etkili olduğu gözlemlenmiştir (Şekil 5).

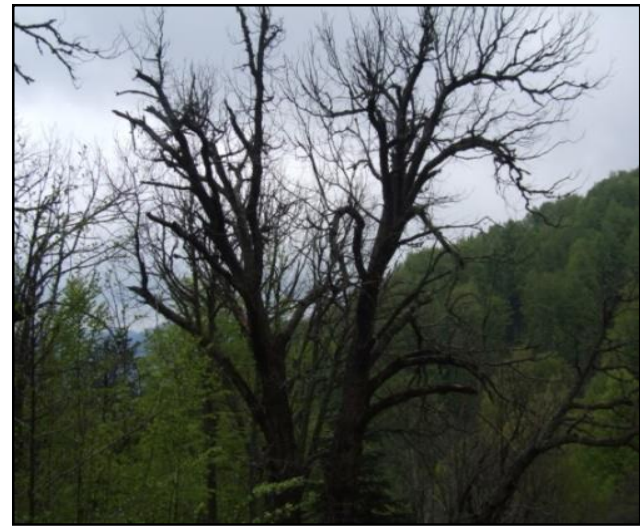

Şekil 5. Kestane alanlarında yaşlı ve kurumuş kestane ağacı örneği

Örnek alanlardaki ağaç adedinin "Çap Basamaklarına" dağılımı incelendiğinde kestanenin $38 \mathrm{~cm}$ 'den başlayarak daha geniş çaplı bireyler olarak temsil edildiği görülmektedir. Daha ince çaplı bireylerde ise diğer ağaç türleri daha fazla temsil edilmekte olup $62 \mathrm{~cm}$ den daha kalın bireylerde ise bu ağaç türleri dağılım göstermemektedir. Örnek alanlardaki gençliklerin vitalite sınıfları ise 45 vitalite sınıfları arasında değiştiği en çok 4 . sinıf vitalite derecesine sahip gençliklerin görüldüğü belirlenmiştir (Şekil 6).

Meşcere profilleri farklı rakımlardan alınmasına rağmen profiller de oluşan gençlik konileri arasında önemli bir fark olmadığ ancak yerleşim yerlerine yakın olan yerlerde veya yollara yakın olan yerlerde gençlik konilerinin oluşamadığı münferit olarak gençliklerin bulunduğu tespit edilmiştir (Şekil 7).

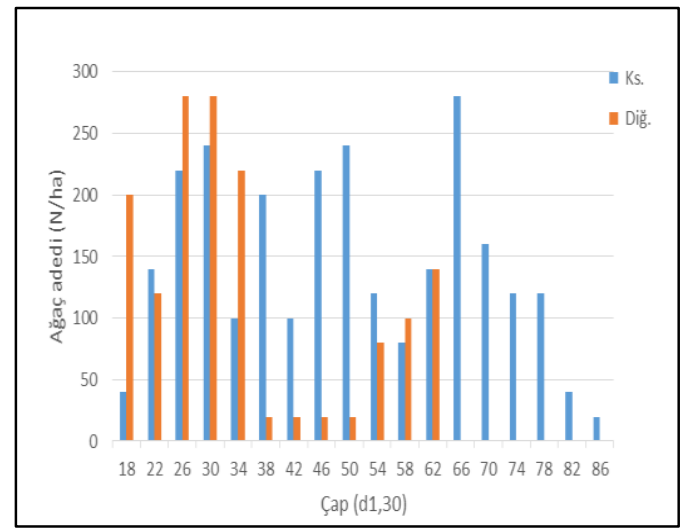

Şekil 6. Örnek alanlardaki Ağaç adedinin Çap Basamaklarına dağılımı 
Tüm yatay profiller incelendiğinde 1şıklanma durumu iyi olan meşcere kısımlarında yeterli miktarda genç birey bulunmakla birlikte özellikle yeterli miktarda 1ş1k almayan ve yüzeyi diri örtü ile kaplı olan yerlerde gençlik oluşumlarının duraksadığ düzensiz veya farklı miktarda 1şı̆̆ın meşcere içerisine girdiği dolayısıyla kök rekabetinin azaldığ 1 yerlerde tipik gençlik konilerinin oluştuğu görülmektedir (Şekil 7).

Tüm örnek alanlar değerlendirildiğinde gençlik konilerinin orta kısmında yer alan bireylerin boy ortalamalarının kenardakilere oranla daha yüksek olduğu belirlenmiştir (Tablo 2). Tüm gençlik konileri incelendiğinde bazı bireylerin yaş ortalamalarının büyük olmasına rağmen boyları arasında fark düşük çıkmıştır.

Yapılan bu araştırmada Meşcere kapalılık derecesinin "gevşek-1şıklı kapalılık" olduğu yerlerde yoğun gençlik gruplarının yer aldığ meşcerenin "tam-sıkışık kapalılık" olduğu yerlerde ise gençliğin daha az yoğunlukta var olduğu tespit edilmiştir. Gençliğin "gevş̧ek1ş1klı kapalılık" derecesinde iyi bir şekilde boy büyümesi yapabildiği gözlemlenmiştir.

\section{Tartışma ve Sonuç}

Anadolu Kestanesi (Castanea sativa Mill.)'nin Kastamonu'da doğal olarak yayılış yaptığı yerlerin genellikle orman arazisi olması vatandaşların bu sahalarda bulunan kestane ağaçlarından üretim yapması doğal kestane meşçereleri üzerinde bask1 oluşturmaktadır.

Meşçere bakımları genellikle kuruyan kestane ağaçlarının sahadan çıkarılması şeklinde gerçekleşmektedir. Meşcere de her dönem devam eden münferit kurumalar nedeniyle "Meşcere bakımı" adı altında müdahaleler yapılamamaktadır. Bunun yerine mevcut kurumalar "olağanüstü hasılat etası" isimli rapor tanzim edilerek sahadan çıkarılmaktadır.

Kuruyan kestane ağaçlarının kesildikten sonra dip kütüğüne ardıç katranı sürülmesi ile veya yeniden sahaya kestane fidanı dikilmek süretiyle kestane meşçerelerinin devamlılığ sağlanmaya çalışılmaktadır.
Ancak bu yöntemlerle kestane silvikültürünün yeterli olmadığı anlaşılmakta ve kestane sahalarının tümünde kestane türünün devamlılığ1 ve verimi artırmak adına silvikültür planları yapılması ve zaman mekan düzenlemesi ile çalışmaların diğer asli türler (Kayın vb.) gibi irdelenmesi gerekmektedir. Tekniğine uygun ve düzenli orman bakımları yapılması sağlıklı ve kaliteli meşcerelerin kurulmasına yardımcı olmaktadır (Saatçioğlu, 1971; Demirci ve ark., 2002; Genç, 2001; Odabaşı ve ark., 2007).

Meşçere kuruluş özelliklerinin bilinmesi ve bu özelliklere dayalı olarak silvikültürel işlemlerin yapılması süreklilik açısından önemlidir. Meşcere kuruluş özelliği doğal afetlere karşı (çı̆̆, kaya yuvarlanması, moloz akışı, heyelan ve sel gibi) etkin bir koruma sağlaması yanında biyolojik çeşitlilik açısından doğa koruma ve yaban hayatı fonksiyonlarına da hizmet etmektedir (Topaçoğlu ve ark., 2008). Ayrıca meşcere kuruluşu ormanlardan elde edilen birçok ürün ve hizmetin işletilmesinde önemli bir rol üstlenirken meşcerenin gelişim modellemesine ve analizine de yardımc1 olmaktadır (Schönenberger'e atfen Topaçoğlu ve ark., 2008). Bu araştırmada da meşçere kuruluş özellikleri ile doğal gençleşme örnekleri arasında belirgin bir ilişkinin olduğu örnek alanlarda meşçere profilleri alınarak tespitler yapılmıştır.

Araştırma alanında ağaç adedinin çap basamaklarına dağılımı incelendiğinde diğer ağaç türlerinin ince çap kademelerinde daha yoğun bir şekilde temsil edilmesi aslında kestane gençliğinin oluşumu ve gelişimi üzerinde olumsuz yönde bir etkisinin olacağı şeklinde değerlendirilebilir. Zlatanow ve ark. (2013) yine aynı tür için benzer bir durumdan bahsetmekte ve kestane gençliğinin kuvvetli rekabete maruz kalacağını ifade etmektedir. 
Tablo 2. Örnek alan verileri

\begin{tabular}{|c|c|c|c|c|c|c|c|c|c|c|c|c|c|}
\hline \multirow[t]{2}{*}{$\begin{array}{l}\text { Örnek } \\
\text { alan }\end{array}$} & \multirow[t]{2}{*}{$\begin{array}{l}\text { Rakım } \\
\text { (m) }\end{array}$} & \multirow[t]{2}{*}{$\underset{(\%)}{\text { Ĕgim }}$} & \multirow[t]{2}{*}{ Bakı } & \multirow[t]{2}{*}{$\begin{array}{l}\text { Ortalama } \\
\text { Çap }(\mathrm{cm})\end{array}$} & \multirow[t]{2}{*}{$\begin{array}{c}\text { Ortalama } \\
\text { Boy }(\mathbf{m})\end{array}$} & \multirow{2}{*}{$\begin{array}{c}\text { Meşcere } \\
\text { Hacmi } \\
\left(\mathrm{m}^{3} / \mathrm{ha}\right)\end{array}$} & \multirow[t]{2}{*}{$\begin{array}{c}\text { Gençlik } \\
\text { Konisi }\end{array}$} & \multicolumn{3}{|c|}{$\begin{array}{c}\text { Gençlik Yaş Ortalaması (yıl) - } \\
\text { Vitalite Sınıfı }\end{array}$} & \multicolumn{3}{|c|}{$\begin{array}{c}\text { Gençlik Boy } \\
\text { Ortalaması (m) }\end{array}$} \\
\hline & & & & & & & & A.K. & O.K. & Ü.K. & A.K & O.K. & Ü.K. \\
\hline \multirow{3}{*}{1} & \multirow{3}{*}{760} & \multirow{3}{*}{40} & \multirow{3}{*}{$\mathrm{K}$} & \multirow{3}{*}{25.6} & \multirow{3}{*}{17.6} & \multirow{3}{*}{284.00} & $1 / 1$ & $12.0-4$ & $10.0-4$ & $8.7-4$ & 4.7 & 4.8 & 4.3 \\
\hline & & & & & & & $1 / 2$ & $8.0-4$ & $6.7-4$ & $6.7-4$ & 4.0 & 3.1 & 4.5 \\
\hline & & & & & & & $1 / 3$ & $11.0-4$ & $10.0-4$ & $8.0-4$ & 4.5 & 3.4 & 4.1 \\
\hline \multirow[t]{2}{*}{2} & \multirow[t]{2}{*}{820} & \multirow[t]{2}{*}{50} & \multirow[t]{2}{*}{$\mathrm{K}$} & \multirow[t]{2}{*}{49.0} & \multirow[t]{2}{*}{17.80} & \multirow[t]{2}{*}{820.00} & $2 / 1$ & $4.3-5$ & $4.0-4$ & $3.7-5$ & 2.5 & 2.1 & 2.2 \\
\hline & & & & & & & $2 / 2$ & $12.7-4$ & $9.3-5$ & $8.0-4$ & 5.4 & 4.4 & 4.5 \\
\hline \multirow[t]{2}{*}{3} & \multirow[t]{2}{*}{860} & \multirow[t]{2}{*}{60} & KB & 36.9 & 15.80 & 582.00 & $3 / 1$ & $12.7-4$ & $9.0-5$ & $11.0-4$ & 4.5 & 5.1 & 5.0 \\
\hline & & & & & & & $3 / 2$ & $4.3-4$ & $5.0-4$ & $4.3-4$ & 1.6 & 1.7 & 1.0 \\
\hline 4 & 745 & 40 & $\mathrm{~K}$ & 40.0 & 17.3 & 246.00 & $4 / 1$ & $8.0-5$ & $6.0-4$ & $7.0-4$ & 3.5 & 3.1 & 3.5 \\
\hline & 780 & 55 & KB & 43.7 & 15.9 & 538.00 & $5 / 1$ & $6.0-4$ & $5.3-5$ & $5.3-5$ & 3.7 & 3.7 & 3.6 \\
\hline 5 & & & & & & & $5 / 2$ & $6.0-4$ & $5.3-5$ & $5.3-5$ & 3.7 & 3.7 & 3.6 \\
\hline & 745 & 65 & KB & 37.5 & 16.0 & 612.00 & $6 / 1$ & $10.7-4$ & $10.0-5$ & $4.7-4$ & 5.9 & 5.5 & 1.5 \\
\hline 6 & & & & & & & $6 / 2$ & $10.7-4$ & $9.3-5$ & $4.7-5$ & 5.6 & 4.5 & 1.5 \\
\hline & 800 & 40 & KD & 58.6 & 16.1 & 622.00 & $7 / 1$ & $3.0-4$ & $4.3-5$ & $4.0-5$ & 1.5 & 2.4 & 2.3 \\
\hline 7 & & & & & & & $7 / 2$ & $3.0-4$ & $4.3-4$ & $4.0-5$ & 1.4 & 2.3 & 2.3 \\
\hline 8 & 820 & 40 & GB & 42.0 & 17.3 & 524.00 & $8 / 1$ & $5.7-4$ & $4.7-4$ & $5.7-4$ & 3.3 & 3.2 & 3.4 \\
\hline & & & & & & & $8 / 2$ & $8.7-4$ & $4.1-4$ & $4.3-5$ & 3.8 & 2.4 & 1.7 \\
\hline 9 & 734 & 30 & KB & 46.9 & 17.0 & 560.00 & $9 / 1$ & $10.7-4$ & $7.3-4$ & $7.7-4$ & 4.0 & 2.9 & 2.8 \\
\hline & 700 & 40 & KB & 49.9 & 14.0 & 898.00 & $10 / 1$ & $2.7-4$ & $3.3-5$ & $4.3-5$ & 1.2 & 1.3 & 1.6 \\
\hline 10 & & & & & & & $10 / 2$ & $6.3-4$ & $6.0-4$ & $6.3-4$ & 2.9 & 2.5 & 2.9 \\
\hline 11 & 340 & 45 & KB & 52.0 & 15.6 & 746.00 & $11 / 1$ & $3.7-4$ & $2.7-4$ & $3.7-4$ & 1.0 & 0.6 & 1.2 \\
\hline & 307 & 25 & KB & 50.7 & 17.8 & 1078.00 & $12 / 1$ & $12.7-4$ & $8.7-4$ & $5.3-4$ & 4.5 & 2.7 & 2.0 \\
\hline 12 & & & & & & & $12 / 2$ & $5.3-5$ & $5.0-5$ & $4.7-5$ & 2.6 & 2.7 & 2.8 \\
\hline & 941 & 30 & $\mathrm{~K}$ & 32.1 & 17.1 & 378.00 & $13 / 1$ & $4.7-4$ & $9.3-4$ & $2.7-4$ & 2.9 & 4.4 & 1.1 \\
\hline 13 & & & & & & & $13 / 2$ & $7.7-4$ & $4.3-4$ & $10.7-4$ & 3.7 & 1.5 & 4.2 \\
\hline & & & & & & & $14 / 1$ & $12.7-5$ & $12.3-5$ & $12.0-5$ & 5.5 & 4.3 & 4.7 \\
\hline 14 & 615 & 40 & GB & 76.0 & 14.8 & 768.00 & $14 / 2$ & $1.3-4$ & $3.3-4$ & $2.3-4$ & 0.4 & 1.1 & 0.9 \\
\hline & & & & & & & 14.3 & $1.7-4$ & $3.3-4$ & $1.7-4$ & 0.7 & 1.0 & 0.5 \\
\hline 15 & 340 & 55 & GB & 39.6 & 17.2 & 546.00 & $15 / 1$ & $10.0-5$ & $9.7-4$ & $8.7-4$ & 3.6 & 3.3 & 3.2 \\
\hline
\end{tabular}




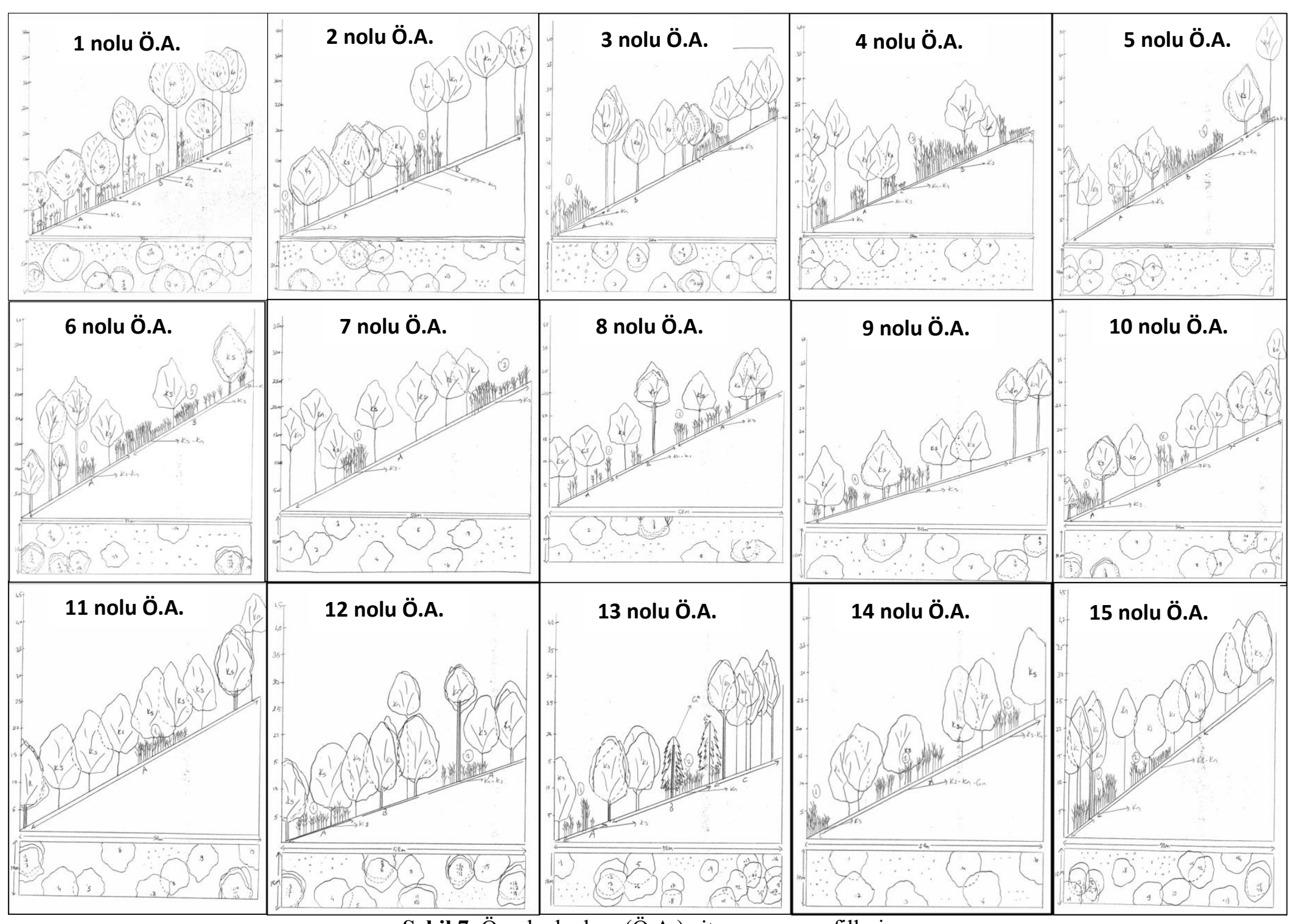

Şekil 7. Örnek alanlara (Ö.A.) ait meşcere profilleri 
Araştırma alanında yeterli boy ve çap artımı olan, iyi canlılığa sahip gençlikler (Vitalite 4) ile çok canlı bir boy ve çap artımı gösteren herhangi bir kusur görülmeyen gençliklerin (Vitalite 5) bulunması diğer vitalite sinıflarının (Vitelite $1,2,3)$ ise görülmemesi ilginç bulunmuştur. Özellikle kapalılığın kırıldığ 1 ve rekabetçi türlerin etkisinden kurtulduğu alanlarda vitalitesi yüksek kestane gençliklerinin varoluşu türün $1 s ̧ 1 k$ isteğinin yeterli oranda karşılanması yanında rekabetin azalmasıyla da açıklanabilir. Nitekim benzer bir durum tipik 1şık ağacı olan Sarıçam için de tespit edilmiştir (Çoban, 2007). Balc1 (2008), Kayın doğal gençliklerinde vitalite ve büyüme formu sınıflarını belirttiği çalışmasında vitalite sınıfı yüksek olan bireylerde büyüme formlarının ve hayatiyetlerinin daha iyi olduğunu gözlemlemiştir. Araştırma alanındaki gençliklerin yeterli sayıda ve vitalitesinin yüksek olması başarılı doğal gençleştirme çalışmaları için önemli bir göstergedir (Kerr, 2000).

Karadeniz orman mıntıkalarındaki diri örtüyü oluşturan Ormangülleri (Rhododendron ssp.), Ayı üzümü (Vaccinium arctostaphylos), Çoban püskülü (Ilex colchica) ve Kara yemiş (Prunus laurocerasus) gibi çalı türleri ormancılık çalışmalarında ciddi problemlere neden olmaktadır (Atay, 1982). Benzer şekilde İnebolu Orman İşletme Müdürlüğü sınırlarında kestane meşçerelerinin doğal olarak gençleştirilmesi veya doğal olarak gelmiş gençliklerle devamlılığının sağlanması önünde en büyük engel sosyal bask1 ve meşçere altında bulunan diri örtü tabakasıdır. Nitekim kestane ağaçlarının tüm meyvelerinin toplanmas1 kestane meyvesi hasatı sirasinda ağaçlara zarar verilmesi ve orman idaresi tarafindan bakımı yapılmayan kestane meşçerelerinin alt tabakasının (diri örtü) ile kaplanması genç meşçerelerin gelişiminde ve tohumların çimlenmesinde önemli bir engel teşkil etmektedir.

Kestane gençliğin alana gelip yerleşmesinde etkili olan 1şı̆̆ı̆, kapalı1ı ğı düzenleyerek yeterli oranda verilmesi, yaşam gücü yüksek gençliklerin oluşmasına yardımcı olacaktır. Yaşam gücü yüksek mevcut gençliğin türün doğal gençleştirme çalışmalarında kullanılması hem genetik çeşitliliğin sağlanması hem de genel gençleştirme süresinin kısaltılması açısından önemlidir. Gençliğin oluşumundan gelişiminde ihtiyacı olan 1şığın sağlanması bireyler arasında rekabetin düzenlenmesine de yardımcı olacaktır.

Sosyal ve ekolojik değeri göz önünde tutulduğunda araştırma sahası için önemli bir tür olan kestane ormanlarında salt faydalanmanın ötesinde uygun silvikültürel müdahaleler ile işletilmesi gerekmektedir. Özellikle son y1llarda biyotik etkenler yüzünden tahrip olan kestane ormanlarının doğal gençleşme özelliklerinin, hangi faktörlere bağlı olarak gerçekleștiği üzerinde sadece araştırma sahası için değil, türün yayılış gösterdiği diğer alanlarda da ayrıntılı araştırmalar gerçekleştirilmelidir.

\section{Teşekkür}

$\mathrm{Bu}$ araştırma Kastamonu Üniversitesi Bilimsel Araştırma Projeleri Koordinatörlüğünce desteklenmiştir. Proje No: KÜBAB 03/2012-11.

\section{Kaynaklar}

Akca, Y. Yilmaz, S. 1999. A study on selection of Castanea sativa in Niksar. Proc 3rd Turkey Natl Hortic Congr 14-17 September, 1999, Ankara, 801803.

Anonim, 2012. Kestane Eylem Planı 2013-2017. Orman Genel Müdürlüğü. Ankara.

Atay, İ. 1982. Doğal Gençleştirme Yöntemleri. İ.Ü. Or. Fak. Yay. No: 306.

Balc1, N. 2008. Kocadüz (Hendek) yöresindeki doğu kayını (Fagus orientalis lipsky) doğal gençliklerinde vitalite ve büyüme formları üzerine araştırmalar. İstanbul Üniversitesi. Fen Bilimleri Enstitüsü. Silvikültür Anabilim Dalı Yüksek Lisans Tezi. İstanbul.

Clark, S., McNab, H., Loftis, D., Zarnoch, S. 2012. American Chestnut Growth and Survival Five Years after Planting in Two Silvicultural Treatments in the Southern Appalachians. USA Forests. 3. 1017-1033.

Çeliker, N.M., Onoğur, E. 2001. Türkiye'de Kestane Kanseri (Cryphonectria parasitica (Murr.) Barr.) Hastalığına Karşı Biyolojik Mücadele Olanakları. Türkiye IX. Fitopatoloji Kongresi. 3-8 Eylül 2001. Tekirdağ.

Çoban, S. 2007. Bolu Aladağ'daki Sarıçam Meşcerelerinde Doğal Gençleşme Örnekleri Üzerine Araştırmalar,. Yüksek Lisans Tezi, İ.Ü. Fen Bilimleri Enstitüsü, İstanbul.

Darabant, A., Chhetrı, P.B., Ra1, P.B., Dorjı, K., Gratzer, G. 2001. Light requirements of the main tree species in Bhutan's conifer belt. Research Report. RNR RC jakar. Special Publication. No.4

Demirci, A., Yavuz, H., Üçler, A.Ö., Oktan, E., Yücesan, Z. 2002. Ülkemizdeki Saf Doğu Ladini Ormanlarında Meşcere Kuruluşları. Büyüme ve Artım İlişkileri ve Silvikültürel Öneriler. TÜBITTAKTOGTAG. Proje No: TARP-2051. Trabzon. 
Erdem, R. 1951. Türkiye'de Kestane Ölümünün Sebepleri ve Savaş İmkanları, Tarım Bakanlığı Orman Genel Müdürlüğü, Sayı 102, Seri 11, Ankara.

Ertan, E., Seferoğlu, G., Dalkılıç, G.G., Tekintaş, F.E., Seferoğlu, S., Babaeren, F., Önal, M., Dalkılıç, Z. 2007. Selection of Chestnuts (Castanea sativa Mill.) Grown in Nazilli District. Turkey. Turk J Agric For 31 (2007) 115-123.

Genç, M. 2001. Orman Bakımı. S.D.Ü Orman Fakültesi Yayınları. No:14/3. Isparta.

Gürer, M. 1999. Kestane Kanseri. K1z1llar Köyü Tarımsal Kalkınma Kooperatifi Kumluca- Bartın.

Karagöz, M., Gençsoylu, Y. 2004. Aydın İli kestane yetiştirme alanlarında zararlı ve yararlı türler ve ekonomik önemleri Türkiye I. Bitki Koruma Kongresi. (08-10 Eylül 2004. Samsun) 109.

Kerr, G. 2000. Natural regeneration of Corsican pine (Pinus nigra subsp. laricio) in Great Britain. J. For. 73, 479-488.

Koyuncu, F., Cetinbas, M., Yildirim, A.N. 2008. Pomological properties and proximate analysis of native chestnut (Castanea sativa Mill.) germplasm from Isparta. Turkey, J Am Pomol Soc 62:98-109.

Liebhold, A.M., McCullough, D.G., Blackburn, L.M., Frankel, S.J., Von Holle, B., Aukema, J.E. 2013. A highly aggregated geographical distribution of forest pest invasions in the USA. Divers Distrib 19:1208-1216.

Lovett, G.M., Canham, C.D., Arthur, M.A., Weather, K.A., Fitzhugh, R. D. 2006. Forest ecosystem response to exotic pests and pathogens in eastern North America. Bioscience 56:395-405.

Odabaşı, T., Çalışkan, A., Bozkuş, F. 2007. Orman Bakımı. İ.Ü. Orman Fakültesi Yayınları. No: 445.

Ozkan, Y. 2003. Investigations on morphological and pomological characteristics of chestnut genotypes in Ikizce and Senbolluk natural areas of Ordu vicinity. Acta Hortic

Saatçioğlu, F. 1971. Orman Bakımı (Meşcere Yetiştirmesine Ait Tedbirler). İÜ Orman Fak. Yayını. No:1636/160. İstanbul.

Serdar, Ü., Soylu, A. 1999. Selection of chestnuts (Castanea sativa Mill.) in Samsun vicinity. Acta Hort.. 494. p: 333-338.

Serdar, Ü. 1999. Selection of Chestnuts (Castanea sativa Mill.) in Sinop Vicinity. Acta Hort. 494. p: 327 332. Serdar U (2002) Chestnut selection in Camili vicinity (Artvin-Borçka). J Faculty Agr OMU 17:5730.

Serdar, U., Demirsoy, H., Demirsoy, L. 2009. Determination of Superior Chestnut Genotypes in the Central Black Sea Region of Turkey. Acta Hortic 815: 37-42.

Serdar, U., Beyhan, N., Demirsoy, L., Demirsoy, H. 2010. Some phenological properties of chestnut genotypes in the Black Sea Region, Turkey. Acta Hortic 866: 135-141.

Smith, D., Larson, B., Kelty, M., Ashton, P., 1997. The Practice of Silviculture: Applied Forest Ecology. Wiley, New York.
Soylu, A., Ufuk, S. 1994. Marmara Bölgesi kestanelerinin seleksiyon yoluyla 1slahı. Sonuç Raporu. Atatürk Bahçe Kültürleri Araşltırma Enstitüsü. Yalova.

Soylu, A., Serdar, Ü., Eratan, E., Mert, C. 2009. Turkey. Following Chestnut Footprints (Castanea spp.) Cultivation and Culture. Folklore and History. Traditions and Uses. Published by ISHS.Scripata Horticulturae N. 9. Year 2009.

Topaçoğlu, O., Bozkuş, F.H., Güney, K. 2008. Ilgaz Dağı Kuzey Bakıda Subalpin ve Yüksek Montan Yükselti Basamağındaki Bazı Meşcere Kuruluşlarının Silvikültürel Özellikleri. Kastamonu Üniversitesi Orman Fakültesi Dergisi. 8 (1) 1-13.

URL 1, 2016. http://www.tuik.gov.tr.

Zlatanov, T., Schleppi, P., Velichkov, I., Hinkov, G., Eggertsson, O., Zlatanova, M., Vacik, H. 2013. Structural diversity of abandoned chestnut (Castanea sativa Mill.) dominated forests: Implications for forest management. For. Ecol. Manage. 291.326-335. 